\title{
THE IMPLICATIONS OF THE USE OF ENGLISH AS A LINGUAL FRANCA ON THE LINGUISTIC CHANGES OF THE COLLOQUIAL DIALECTS OF ARABIC
}

\author{
(A Sociolinguistic Analysis of the use of English loanwords in Saudi Colloquial Arabic)
}

\author{
Abdulfattah A. Omar ${ }^{1}$ \\ Prince Sattam Bin Abdulaziz University
}

\begin{abstract}
With the development of globalization and the emergence of global English, numerous studies have been concerned with the ways Arabic is influenced by English, the adoption of many English loanwords by Arab speakers and the dominance of English as a lingua franca in different Arab countries including Saudi Arabia. These studies generally investigate the effects of global English on the Arab linguistic and cultural identity. The majority of these studies tend to list what they refer to as risks of the dominance of English loanwords in Arabic and assert the importance of keeping Arabic pure from these words which are described as ذخيل dakhil (literally meaning strange and outsider). Very few studies have been done on exploring the ways English loanwords are used in Saudi Colloquial Arabic (SCA) and the relationship between the use of English loanwords and some sociolinguistic variables such as sex, age, geographic location, and education. In the face of this, this article is concerned with exploring the relationship between sex and the use of English loanwords in Saudi Colloquial Arabic (SCA). In order to do this, the study is based on a corpus of English loanwords in Saudi Colloquial Arabic (SCA) with the purpose of investigating the frequency of English loanwords in the speeches of male and female speakers and describing the morphological adaptations used by male and female speakers. Results indicate that there are significant differences between Saudi male and female speakers in the use of English loanwords in terms of frequency, topics, and morphological adaptations. The sex or gender of the speaker is an important factor in determining the frequency, distribution, and the morphological adaptations of English loanwords in SCA.
\end{abstract}

Keywords: Loanwords. Gender. Linguistic diversity. Language use. Sociolinguistic analysis. Saudi colloquial Arabic

Recebido em: fevereiro 2017

Aceito em: fevereiro 2018

DOI: $10.26512 /$ les.v19i2.16894

\section{INTRODUCTION}

This article is concerned with investigating the relationship between sex and the use of English loanwords in Saudi Colloquial Arabic (henceforth, SCA) in relation to the frequency of English loanwords, the topics where English loanwords are used by males and females, and the morphological adaptation processes that are carried out by both male and female speakers when these loanwords are incorporate into SCA. The aim is to describe the process of English loanword integration in SCA, identify the dominant fields and topics where English loanwords are most widely used, and explore whether there is a correlation between sex and the use of English loanwords in SCA. The hypothesis is that gender is one of the main social variables that plays an

\footnotetext{
${ }^{1}$ Abdulfattah Omar finished his PhD in English language and linguistics in Newcastle University in 2010. Since then, he has been teaching English language and linguistics in a number of British, Egyptian and Saudi universities. His research interests include sociolinguistics, digital humanities, and discourse studies. E-mail: a.a.omar2010@gmail.com
} 
important role in linguistic diversity and the adoption of loanwords (Meyerhoff, 2015; Philips et al., 1987, Talbot, 2010, Trudgill, 2000) which usually lead to language changes (vowel/consonant change, grammatical gender, number, pluralization, etc.) within the linguistic system of the by speakers of the recipient language (Philips et al., 1987, Irwin, 2011). This study investigates a corpus of SCA in order to explore how English loanwords are used by Saudi speakers and to see whether sex has any role in linguistic variation and use of English loanwords in SCA.

It has been observed that the volume of English loanwords in Arabic has recently increased in an unprecedented manner due to the dominance of English as a global language. This has resulted in what can be called linguistic expansion of the Arabic vocabulary (Al-Sameray, 2011, Ibrahim, 2006, Ismaeel, 2005, Hashim, 2011). This linguistic phenomenon reflects, in one way or another, the contact between English and Arabic. In this, many studies addressed the issue of contact between English and Arabic and how the two languages have been influenced by each other. In spite of the prolific literature concerning the contact between English and Arabic and more specifically in relation to the issue of English as a global language and its influence on Arabic, very little has been done on linguistic diversity in relation to the use of English loanwords in SCA. To put it into effect, many studies have been concerned with what they call risks of the dominance of English as a global language and the increasing use of English as a lingual Franca on the Arab linguistic and cultural identity. On the other hand, very little has been done in relation to the description, investigation, and exploration of the sociolinguistic aspects and use of English loanwords in SCA. In the face of this, the present study is concerned with addressing this gap in literature by investigating the role of sex in linguistic diversity in relation to the use of English loanwords in SCA.

This article is in 8 main parts. Part 1 is the present introduction. Part 2 defines the research problem and asks the research questions. Part 3 is a review of the concept of loanwords and the linguistic system in Saudi Arabia. Part 4 describes the research methods and procedures. Part 5 is data analysis. Part 6 is a discussion of the results. Part 7 is conclusion. Part 8 is limitations and recommendations of the study.

\section{STATEMENT OF THE PROBLEM}

In his book English as a Global Language, David Crystal (2003) argues that cultural globalization has significant influences on world languages leading to language changes within these languages. This is due to the idea that there is a correlation between language and culture. According to Labov (2011), changes in cultural patterns then lead to linguistic changes. In this way, 
Hashim (2011) argues that cultural globalization has led to drastic and unprecedented changes within Arabic over the last years and that the main bulk of these changes can be clearly observed within Arabic vocabulary which absorbed. Al-Sameray (2011) attributes the introduction of many loanwords into Arabic to what he refers to as biculturalism. He explains that with the emergence of globalization, many Arab citizens have come to be influenced by the Western and English culture and come to adopt different English loanwords which have equivalents in Arabic. Likewise, Ismaeel (2005) argues that the dominance of the American culture due to globalization has resulted in the adoption of numerous American words and expressions by speakers of Arabic. She adds that the adoption of English loanwords has led to linguistic changes within the patterns and structures of Arabic. She thus relates language changes within Arabic over the recent years to cultural factors and particularly to cultural globalization.

Although there has always been resistance from many Arab scholars and linguists to the adoption of foreign and English loanwords in Arabic who argue that it has negative implications on the Arab linguistic and cultural identity, linguistic changes within Arabic as a result of the adoption of English loanwords are inevitable. This resistance may explain the reason that very little studies have been done on exploring the linguistic aspects of the adoption of loanwords in Arabic. The majority of studies focus mainly on the reasons behind the adoption of loanwords and its effect on the identity of native speakers of Arabic. Arabic is highly celebrated in the Arab world and Saudi Arabia as it is the language of the Holy Quran and Saudi Arabia itself is the location of the Holy Mosque and the motherland of Islam and the Quran. In this way, the majority of these studies link the adoption of English loanwords to what they call corruption of Arabic and the loss of the Arab and Muslim identity. Other studies have been concerned with addressing the problems related to loanwords in translation studies(Baker, 1987, Qinai, 2000). In this way, different linguistic aspects of the adoption of loanwords in Arabic have been ignored. Furthermore, there are no adequate studies that have tended to explore the relationship between sex, education, and/or social class from one side and the adoption of loanwords in Arabic in general and SCA in particular. The majority of studies addressed either Modern Standard Arabic (MSA) or Egyptian Arabic, one of the major and most widespread dialects of Arabic (Ibrahim, 2006, Hafez, 1996, Moshref, 2009, Khalil, 1984, Hassan, 2015). The issue of the adoption of loanwords in Arabic is still one of the most controversial ones in the Saudi academic and religious circles(Al-Sameray, 2011, Hashim, 2011, Ismaeel, 2005).

In the light of the above mentioned problems, this article attempts to describe the use of English loanwords in Saudi Colloquial Arabic. The study intends to explore whether Saudi speakers prefer to use English loanwords instead of the Arabic equivalents and whether gender is a 
significant variable in relation to the use and linguistic adaptation of English loanwords in SCA. The main research question of this study can be asked as follows.

What is the relationship between gender and the use of English loanwords in Saudi Colloquial Arabic?

This question leads to some other questions. These include

- What is the ratio of English loanwords to their Arabic equivalents?

- What are the reasons behind the use of English loanwords? Is it prestige, for example? And is it related to gender issues?

- What are the morphological adaptations of English loanwords in Saudi Colloquial Arabic and whether gender has a role in these processes? In other words, do men and women use English loanwords in a different morphological manner?

\section{Literature REVIEW}

The issue of loanwords has always been a controversial one in language studies since it is always associated with issues of linguistic awareness and national identity. With the linguistic expansion of English in the $18^{\text {th }}$ century, for instance, Dr. Samuel Johnson set the first English dictionary to preserve English from the dominance of lexical borrowing. With the development of descriptive linguistics, however, the phenomenon of lexical borrowing, including the adoption of loanwords, has been generally considered one of the inevitable characteristics of human language. Haugen (1950) argued that loanwords are accepted and regularly used in almost all languages. Romaine (1989) agrees that loanwords are used by almost all speakers even if they do not know a foreign language. He argues that bilingualism or the knowledge of a foreign language is not a requirement for the use of loanwords. It is a matter of language contact after all. Millar (2007) puts it clearly that it is highly unlikely that a language finds itself in complete isolation from other languages.

The implication is that contact between cultures and languages leads definitely to borrowing between languages. This is the case with all human languages and the idea is as old as language itself. In this context, Arabic is no exception to the process of linguistic borrowing. English itself is a result of language contact between the people (mainly the Angles, Saxons, and the Jutes) who came from Northern Europe in fifth century and the Britons who were the indigenous inhabitants of the British Isles (Baugh and Cable, 1989). There was nothing to be called English before the conquest of Britain by the Angles, Saxons, and Jutes (Campbell, 2013). In their book 
Loanwords in the World's Languages, Haspelmath and Tadmor (2009) stress the role of language contact and globalization in the adoption of loanwords in different languages.

Crystal (2003) argues that globalization has led to the arrival of unprecedented numbers of English loanwords into other languages. He asserts that the emergence of English as a global language can influence the structure of other languages especially by providing a fresh source of loanwords for use by these other languages. Crystal also points out how languages like Arabic and Chinese were once used as global languages and had tremendous influence on other languages. The implication here is that the adoption of loanwords is closely related to language contact and globalization is playing a vital role today in the introduction of many English loanwords to almost all world languages including Arabic. In this, different studies have been concerned with addressing the issue of English loanwords in Arabic and the role of globalization in the increasing use of English loanwords in Arabic. This study is not, however, concerned with the reasons of the adoption of English loanwords in Arabic. It is limited to the study of some linguistic diversity in relation to the use of English loanwords in SCA.

A loanword is simply a word in one language that has been borrowed from one language and incorporated into another language (Durkin, 2015). In this, Hafez (1996) suggests that the term has always been associated with the concept of lexical borrowing. She argues that while some studies use the two terms interchangeably, lexical borrowing is broader. She explains that lexical borrowing is an umbrella term that compromises different types including loanwords, loan forms, loan shifts, and loan blends" (1996:383). According to Kemmer (2004), loanwords can be defined as words adopted by the speakers of one language (the recipient/target language) from a different language (the source language) without being translated in that recipient or target language. In other words, loanwords or lexical borrowing are taken from a foreign language into another by its native speakers. In this way, loanwords have a significant influence on the development and change of languages. The idea is simply that all languages borrow words from other languages. At the beginning, recipient languages generally consider as loanwords and finally they treat them as if they were their own.

According to Thomason (2001), there is a close relationship between linguistic borrowing and language change. She argues that borrowing of words, which are referred to as loanwords, from other languages that is the most common type of change that is taking place. That is why; lexical borrowing has always been a controversial issue in almost all languages for its consequences. In almost all languages, there are always many critics, scholars, and policy makers who stand against lexical borrowing. In the Netherlands today, for instance, there is a public unrest that the dominance of linguistic borrowing of English loanwords will ultimately result in the disappearance of Dutch 
(Booji, 2001; Zenner, 2015). Similarly, there is always strong resistance to lexical borrowing in Arabic. Arabic is the language of the Holy Quran which is one of the main components of Islam. Also, it is the language of the Prophet Muhammad's sayings (Hadith) peace and blessings of Allah be upon him. Quran and Hadith represent a great importance to Muslims since they are the main sources of regulations in Islam. Accordingly, many religious leaders and scholars resist any change within Arabic. In this way, the issue of linguistic borrowing has always been a controversial one in the Arabic linguistic circles.

\subsection{Loanwords vs. borrowing}

Hoffer (2002: 1) defines borrowing as "the process of importing linguistic items from one linguistic system into another, a process that occurs any time two cultures are in contact over a period of time". According to Yule (2006), linguistic borrowing is one of the most important and widely used processes for creating new words in all languages. It is, Armstrong (2005) argues, a way that a language renews its lexicon. Throughout its long history, Arabic, just like all other languages, has tended to borrow from other languages (Chejne, 1969; Gu, 2013; Versteegh, 2014). Qasim (2009) argues that in Classic Arabic (which was spoken in the Arab Peninsula, Kingdom of Saudi Arabia now), so many Persian and Hindi words were borrowed into English and came to be used as Arabic words. As the history of Arabic shows, these words underwent a process that is described as Arabizing (borrowed words) or Arabization. It is even argued that the Quran itself, which is the holy book of Islam and which is highly appreciated by all Muslims all over the world, used different borrowed words which are not pure Arabic words. Yarshater (1998) argues that so many Persian words came into Arabic prior to Islam and with the revelation of the Quran, many of these Persian words were used in the Quran itself. Similarly, Versteegh (2014) argues that the Quran contains a number of foreign loanwords that came into use in the Arab Peninsula during the period of the development of Classical Arabic that preceded the appearance of Islam. In this way, these borrowed words, referred to as Arabized words المعرب, became words within the Arabic lexicon. There is no controversy concerning the use of these words.

It is known that the majority of people living in the Arab Peninsula converted to Islam and these Arabs conquered many countries either in the East or the West. As a result, Arabic was used as the official language in many of these countries. This however led to the emergence of many dialects of Arabic and many foreign words found their way into the Arab peninsula itself. In the face of this, many Arab scholars called for the preservation of Arabic from corruption. They asked Arab speakers to use Perfect Arabic which is the language of the Holy Quran and not to use foreign 
words which are referred to as Dakhil meaning strange and outsider. The indication is that these words are extrinsic and not welcome.

In spite of all the social, economic, cultural, and political changes that have influenced Arabic, many Arab scholars still use the term to refer to any borrowed word from any other language into Arabic. For these scholars, dakhil words should not be used since they are not Arabic words. Arab speakers should use the Arabic equivalents of such words. For words that have no Arabic equivalents, they suggest muwallad المولد. That is, they suggest that some Classic Arabic words can be used to convey these new meanings.

Their resistance to lexical borrowing is based on the argument that the lexical expansion of Arabic and the adoption of borrowed words will lead to the death of Classic and Standard Arabic words and the language of the Quran will not be understood by future generations. They argue that the new versions of Arabic will be completely different from the language of the Quran. The history of English is always given as an example. They argue that Old English is now a dead language and the majority of native speakers of English cannot understand a text written in Old English. In this sense, English and other loanwords are described as dakhil since they are not included in the Arabic lexicon.

\subsection{Loanwords and code-switching}

In sociolinguistics, the concept of loanwords has always been associated with codeswitching. This is simply a process whereby speakers switch back and forth between two or more languages. Just like loanwords, code-switching, Myers-Scotton (2006) argues, is also a language contact phenomenon. However, it is related to particular types of bilingual speech communities. Wardhaugh and Fuller (2015) explain that code-switching takes place when the languages used change according to the situations where the speakers find themselves. In given situations, speakers alternate between two or more varieties. According to Auer (2003), code-switching has social, cultural and communicative functions. The main difference between code-switching and the adoption of loanwords, Sachdev and Giles (2004) argue, is that the adoption of loanwords is not limited to bilingual communities. It is not a requirement that a speaker is bilingual to use loanwords. In order to illustrate the point, let's take this example. The use of both French and Arabic in Morocco is described as code-switching since it is a bilingual community where both French and Arabic are spoken. For social reasons, speakers alternate between French and Arabic. However, the use of English words within Arabic or French is described as a process of adopting English loanwords. 


\subsection{Lexical borrowing and loanwords in Saudi Colloquial Arabic}

The unprecedented spread of global communication channels and social media has dramatically fostered linguistic borrowing across the world. Commenting on this linguistic reality, Graddol (2004) asserts that languages undergo rapid changes due to demographic trends, new technology, and international communication. Unavoidably, globalization has dramatically increased intercultural encounters; which in turn, has fostered word-loaning across the languages. Numerous English loanwords have spread in many languages including Arabic. Through its long history, Arabic has influenced and been influenced by many other languages including Spanish and English. Hofer (2002) asserts that Arabic is one of the languages that have had an overwhelming significance as carriers of languages. He illustrates that so many Arabic words came into Spanish over centuries of Arabic occupation. The implication here is that there is always a close relationship between political and cultural power of language and lexical borrowing. During the period of Arab Renaissance, Arabic was a powerful language that influenced other languages. In this context, Cannon (1994) traced the influence of the lexical borrowing of Arabic on English. He asserts that by means of lexical borrowing, so many Arabic words are still widely used in English. During this period, Crystal (2003) argues, Arabic was a global language. Similarly, Taylor (1933), in his book Arabic Words in English, noted that English Language borrowed about a thousand words from Arabic and there are thousands of derivatives from these words. Today, Arabic is greatly influenced by English since the latter is now the global language. This explains the relationship between economic and political power on the one side and the dominance of a language on the other hand (Darwish, 2015).

In spite of the prolific literature in the influence of English loanwords on MSA and other Arabic dialects including Egyptian Arabic and Jordanian Arabic (Abushabib, 2016; Hafez, 1996; Suleiman, 1985), very little has been done on Saudi Arabic. Different studies assert that English loanwords are now widely used in colloquial Arabic in different regional dialects of Arabic which are not classified as MSA which are usually described as colloquial Arabic (Rosenhouse and Kowner, 2013). It should be noted that in Arabic, there is a big difference between and colloquial dialects of Arabic and MSA. MSA is a highly formal version of Arabic. It is used almost in the same way by all Arab speakers. It is the sort of language used in the press, news bulletins, education, and academia (Holes, 2004; Ibrahim, 2009).

In surveying the literature concerning the use of English loanwords in the Saudi dialect or what is referred to as Saudi Arabic, it has been found out that the majority of studies are concerned with MSA in terms of the mutual contact between Arabic on the one hand and other languages such 
as English, French, Hindu, and Persian. The implication is linguistic and religious circles still insist that only standard Arabic should be studied. Many linguists believe that colloquial dialects are not in a position to be linguistically studied. Nevertheless, the recent years have witnessed the birth of new attempts to study the sociolinguistic aspects of the Saudi version or dialect of Arabic and the emphasis of the descriptive nature of language. For hundreds of years, the study of Arabic was confined to prescriptive rules.

In an investigation of the main sources of foreign loanwords in SA today, Kashgary (2014), argues that there are three main sources of foreign loanwords in SCA. These are English, French and Italian in order. He explains that the majority of foreign loanwords in SCA are borrowed from English. These are words that are science and technology. He adds that French comes second where Saudi speakers tend to use French loanwords in talking about fashion, etiquette and arts. Italian comes third with loanwords that refer to opera and Christianity. In a more recent study, Alahmadi (2015) investigated the relationship between social factors including sex, age, and education on one side and the adoption of loanwords in Arabic. The study is limited to Meccan Hijazi Dialect and there is no explanation of the linguistic changes within English loanwords when incorporated into Saudi Arabic.

The main idea of this discussion is that there is a close relationship between lexical borrowing and the adoption of loanwords on the one side and the political and cultural power of languages. Recipient languages usually borrow from powerful languages. Today, the use of English as a global language has significant influence on almost all world languages including Arabic. Discussions also indicated that in Saudi Arabia, there have been different forms of rejection to foreign loanwords in Arabic for linguistic and cultural identity reasons. Many linguists and religious leaders urge people to keep Arabic pure from any dakhil words دخيل (foreign loanwords). According to them, Arab speakers have to speak perfect Arabic, the language of Quran so that they can understand its meanings. In the recent years, however, there is a tendency of linguists and scholars to address the descriptive properties of Arabic language. They have come to reject the long established tradition of the prescriptive study of Arabic.

\section{RESEARCH DESIGN AND METHODS}

In order to answer the research questions, this study is based on a sample of Saudi Colloquial Arabic SCA. A corpus of the English loanwords in SCA and their Arabic equivalents is built for the purposes of the study. The study is based only on spoken data. The rationale is that spoken data is more likely to be spontaneous. Furthermore, in Arabic, there is a great difference 
between spoken dialects of Arabic and written Arabic. Arab speakers tend to use more casual kind of language in their everyday communication while tend to use more formal language in writing. Many English and foreign loanwords do not even appear in writing.

The evening TV show Audience Contest on the Saudi official TV (Channel 1) is used for the purpose of the study. The program is based on audience participation and calls answering the anchor's questions. These are a variety of questions in different areas including history, sports, politics, geography, arts, and cinema. Winners receive cash awards and sometimes cars. The program is broadcasted during the holy month of Ramadan, the most watched time in Saudi Arabia.

Participants of this study are only Saudi males and females whose first language is Arabic. There is no selectivity in data collection. That is, the study will include all the English loanwords (and their Arabic equivalents where available) used by Saudi speakers during the given period so that there is no bias. Ethical issues are also considered.

300 participations are selected for the purposes of the study. Each conversation usually takes 2-3 minutes. For time limits, presenters usually end the call if they think it can exceed 3 minutes. Conversations were randomly selected. However, gender representation and topic were considered. The entries of all the presenters were excluded. The reason is that presenters may be conscious of what they are saying. Some may be under the pressure of using Modern Standard Arabic (MSA). In Saudi Arabia, many media commentators urge TV and radio anchors and presenters to use only MSA. By the way, MSA is the sort of language used in news bulletins and different programs and shows. The rationale is that the language used by the presenters may not be spontaneous which may affect the reliability and validity of the results.

The corpus included only the English loanwords that have Arabic equivalents that participants used. In this, a clean list was developed. It excluded all Arabized words such as democracy, liberal, liberalism, academy, microwave, film, video, cinema, shampoo, cream, fax, battery, and microphone. The clean list also included the website names of Google, YouTube, Facebook and Twitter. Although the last two names are sometimes given Arabic names, they are not used in a normal way and are not known in SCA. After executing the clean list, the final corpus was created. English loanwords were classified based on the topic/theme. These include social media, education, household items, colors, fashion and clothes, and electronic devices.

A frequency analysis will be conducted for the selected loanwords and ratios of male and female speakers will be compared. Linguistic adaptation processes (consonant/vowel change, grammatical gender assignment, number, pluralization, etc.) of the English loanwords will also be described. It will be seen also whether there is correlation between sex and the linguistic adaptation 
processes. In other words, the analysis will explore whether there is linguistic diversity in relation to the way English loanwords are used in SCA.

\section{AnAlysis}

As indicated in the figures 1-2 below, the use of English loanwords outnumbers the Arabic equivalents. The total number of English loanword frequencies is 2409 while the total number of the frequencies of their Arabic equivalents is only 1088.

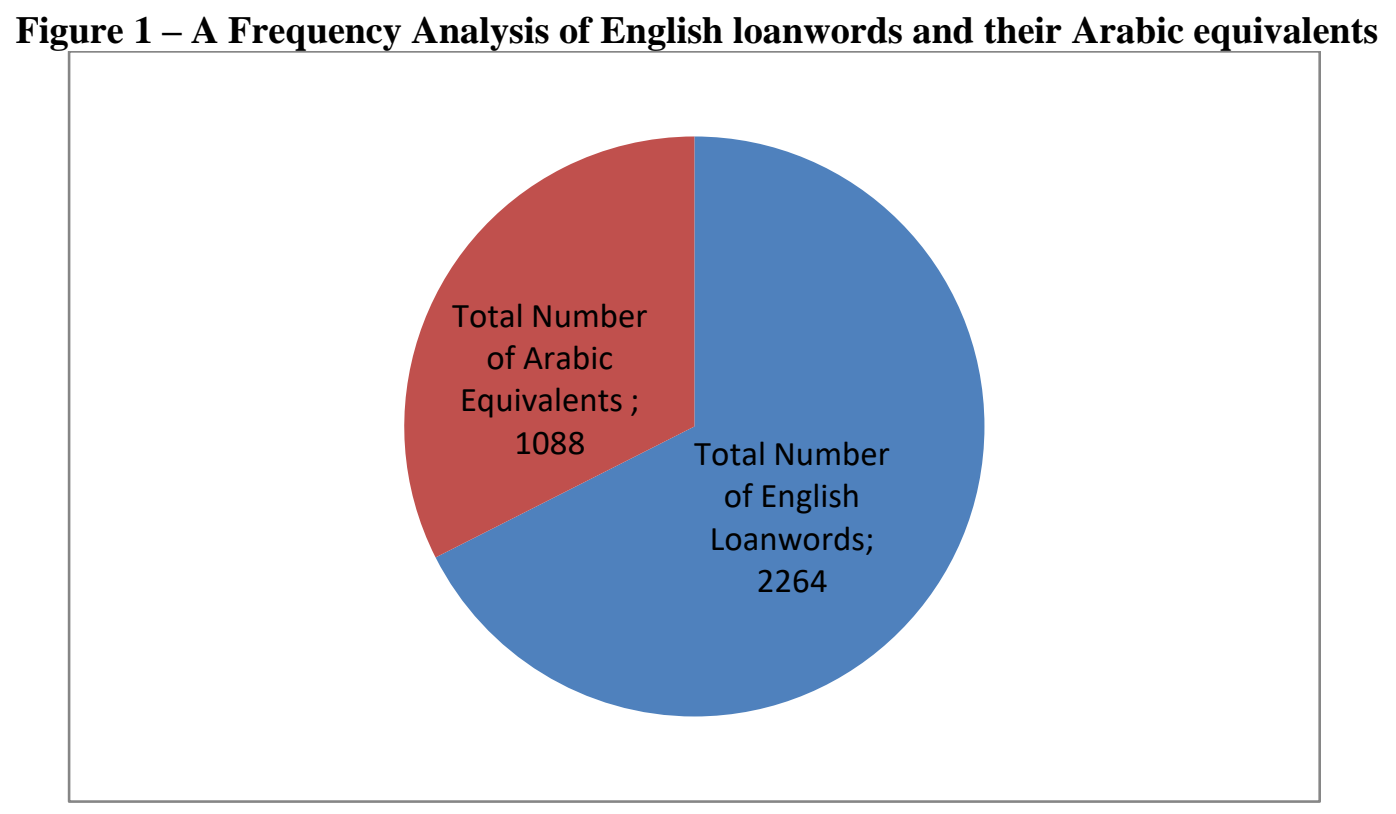

Based on the above statistics, it is obvious that the frequency of the use of English loanwords is much higher than the use of their Arabic equivalents. The ratio of English loanwords to Arabic equivalents is roughly 2 to 1 . The ratio analysis here means the number of English loanwords for the Arabic equivalents. 
Figure 2 - The ratio of English loanwords to Arabic equivalents

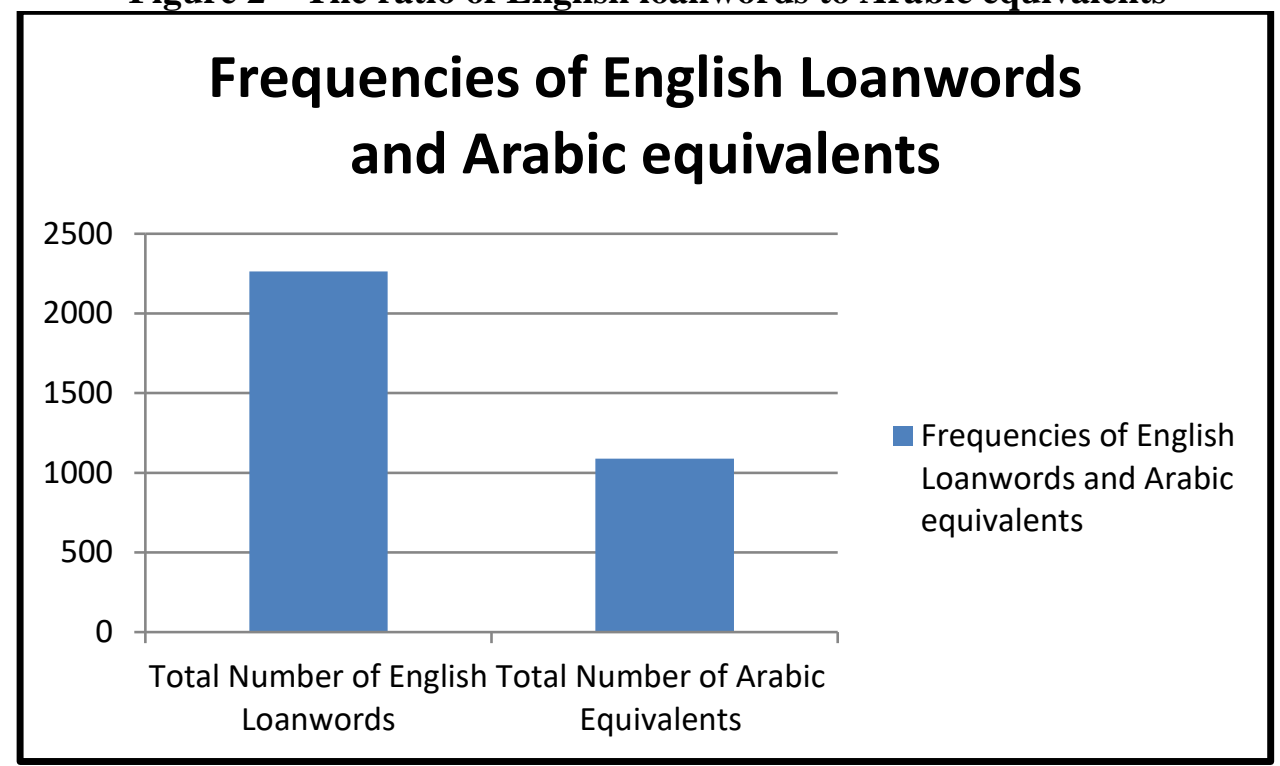

Generally speaking, Saudi speakers use English loanwords more than Arabic equivalents in their greetings and talking about social media, football, computer, technology, banking, and fashion. However, the ratio of English loanwords to Arabic equivalents is different from one topic to another. This is illustrated in Table 1below.

Table 1 - English loanwords and their Arabic equivalents in the speeches of Saudi speakers

\begin{tabular}{|l|l|l|}
\hline Topics & $\begin{array}{l}\text { English } \\
\text { loanwords }\end{array}$ & $\begin{array}{l}\text { Arabic } \\
\text { equivalents }\end{array}$ \\
\hline $\begin{array}{l}\text { Computer \& } \\
\text { technology }\end{array}$ & 358 & 241 \\
\hline Social media & 525 & 174 \\
\hline Clothes \& Fashion & 160 & 24 \\
\hline Greetings & 692 & 197 \\
\hline Education & 100 & 36 \\
\hline Banking & 82 & 55 \\
\hline Sports \& Football & 207 & 156 \\
\hline Miscellaneous & 32 & 50 \\
\hline Foods \& Drinks & 145 & 65 \\
\hline Cinema \& Music & 108 & 90 \\
\hline
\end{tabular}

Concerning the distribution of English loanwords in the selected data, results indicate that the most frequent English loanwords are assigned to greetings, social media, computer, and technology respectively as shown in Figure 3 below. 
Figure 3 - A distribution of English loanwords in SCA

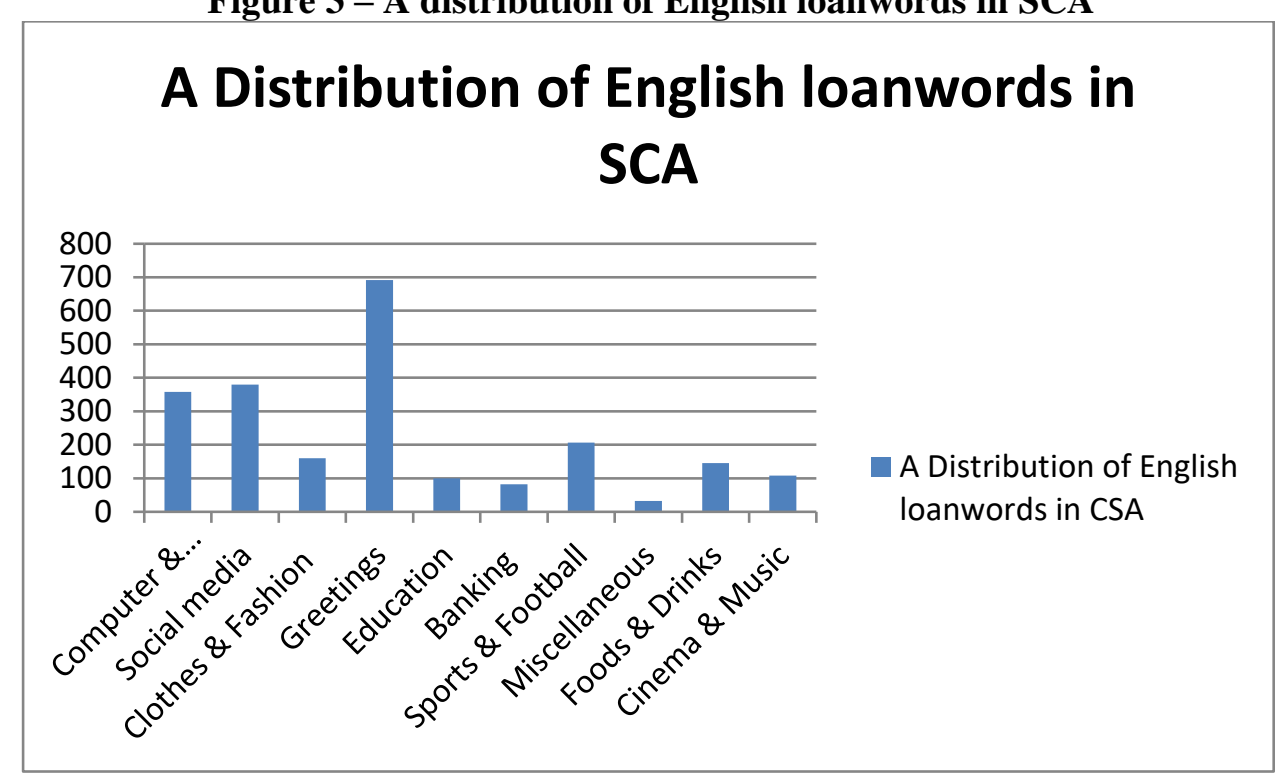

The ratio of English loanwords to Arabic equivalents, however, is different from one topic to another. This can be seen in Figure 4 below.

Figure 4 - The ratio of English loanwords to their Arabic equivalents

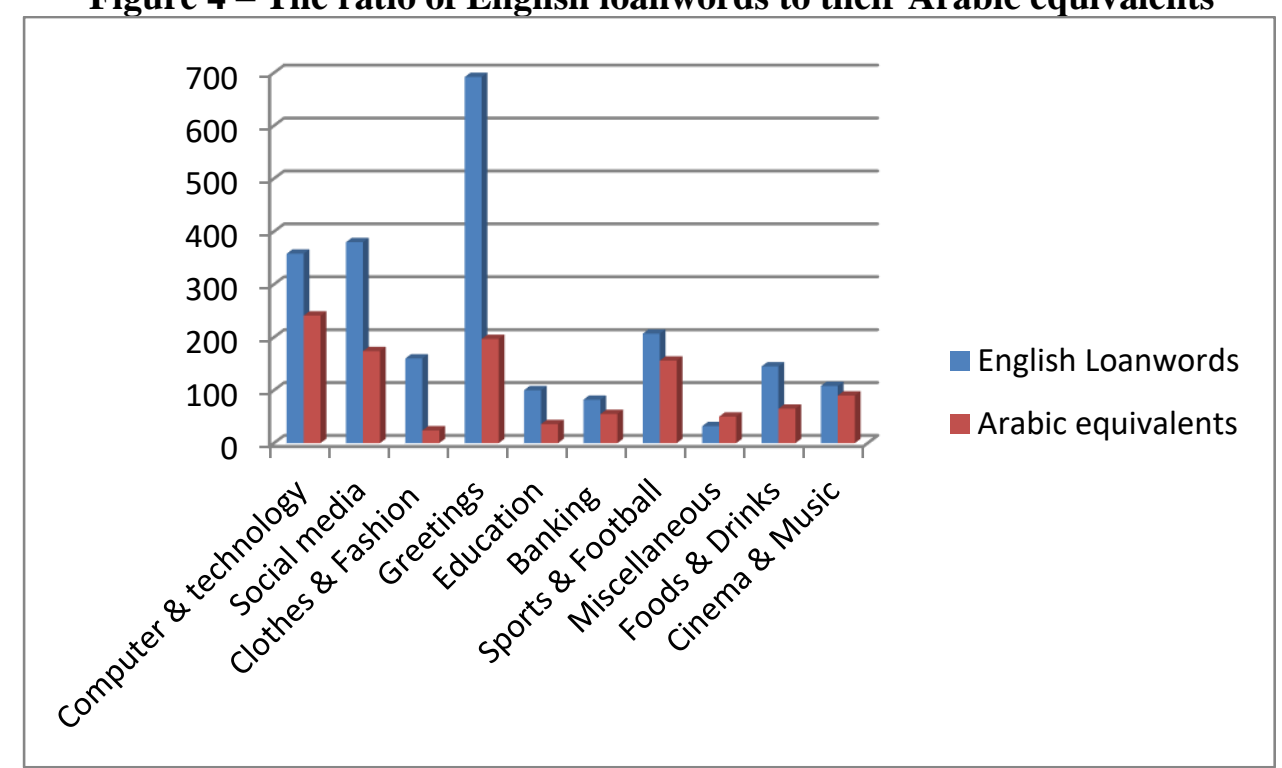

In the above figure, it is clear that Saudi speakers prefer to use English loanwords in expressing greetings and talking about fashion, computer, technology, and social media. There is a slight difference between the use of English loanwords and their Arabic equivalents in talking about cinema, music, sports, and banking. An interesting feature in this connection is that the highest/largest ratio between English loanwords and their Arabic equivalents. This can be clearly seen in Figure 5 below. 
Figure 5 - Expressing fashion in SCA

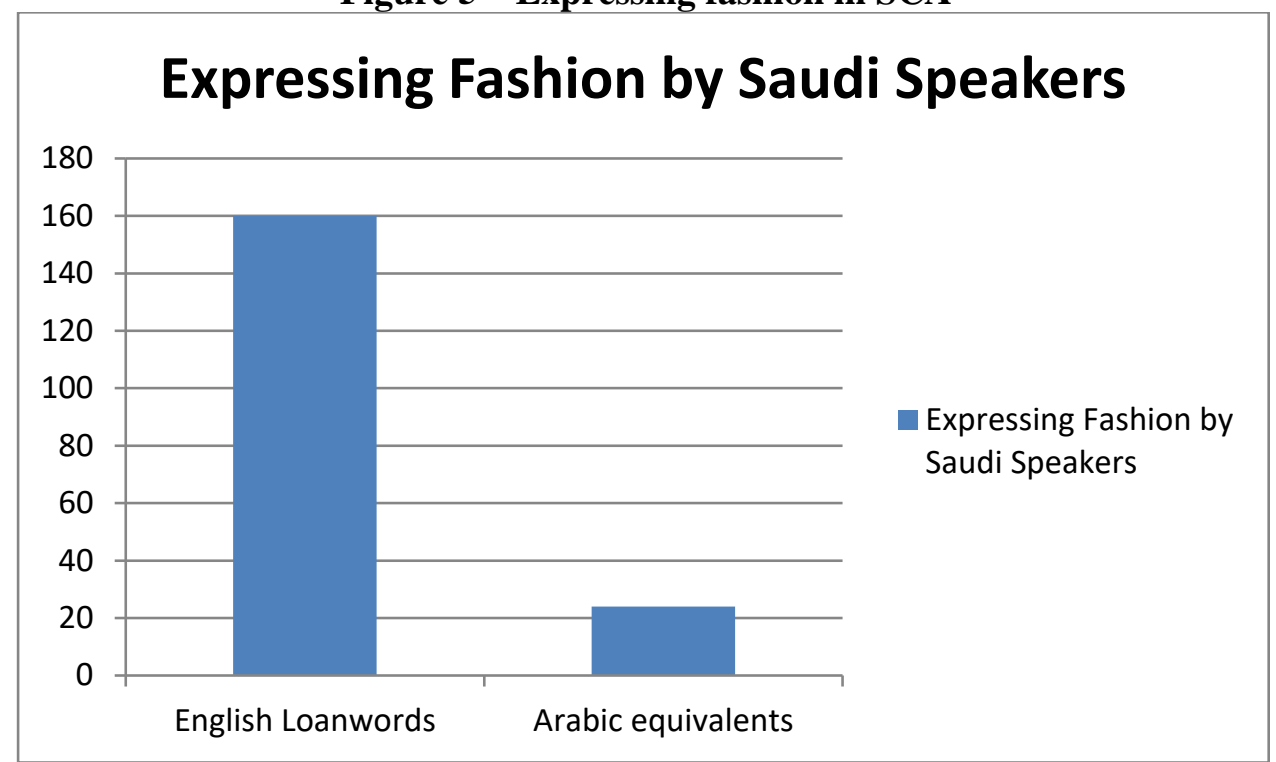

The ratio of Arabic equivalents to English loanwords in SCA is relatively 1to 7 (1:7). The use of English loanwords is around 7 times (or more specifically 6.6 times) larger/higher than the Arabic equivalents. The ratio of English loanwords in expressing greetings as compared to the Arabic equivalents comes second. The ratio of Arabic equivalents to English loanwords in greetings is around 1 to $3(1: 3)$. This means that the use of English loanwords in expressing greetings is around three times higher/larger than the use of Arabic equivalents.

In relation to sex, statistical frequencies indicate that women generally use English loanwords more than men do. Female speakers used $56 \%$ out of the English loanwords while male speakers used only 44\%. This is seen in Figure 6 below.

Figure 6 - A comparison between male and female speakers in relation to the use of English loanwords

\section{A comparison between male and female speakers in the use of English loanwords}

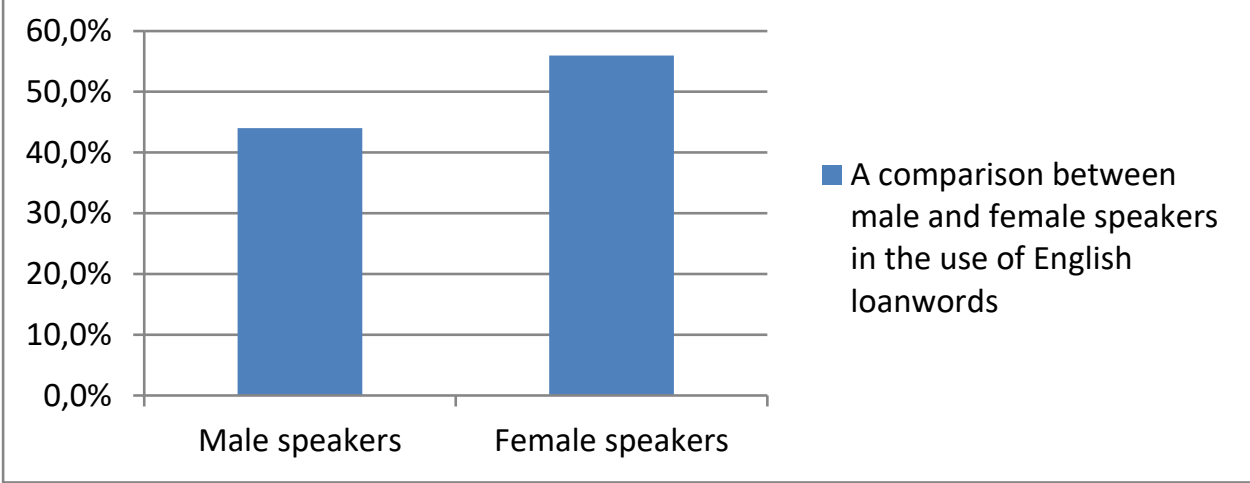


It has also been observed that women use Arabic equivalents less than men do. This suggests that women are more interested in using English loanwords. This is shown in the figure below.

Figure 7 - Frequencies of Arabic equivalents in male and female speeches

\section{Frequencies of Arabic equivalents in male and female speeches}

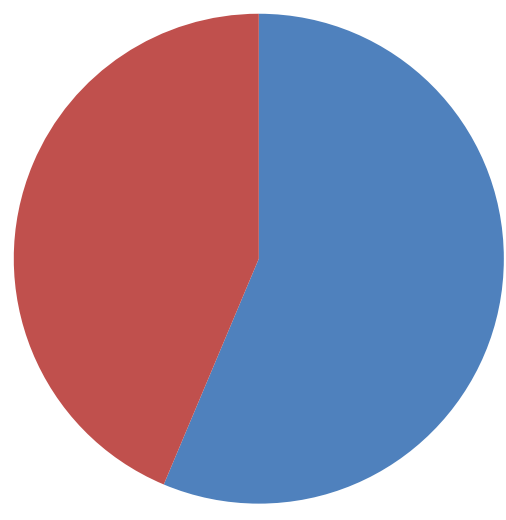

Male speakers

- Female speakers

Figure 8 - A comparison between male and female use of Arabic equivalents

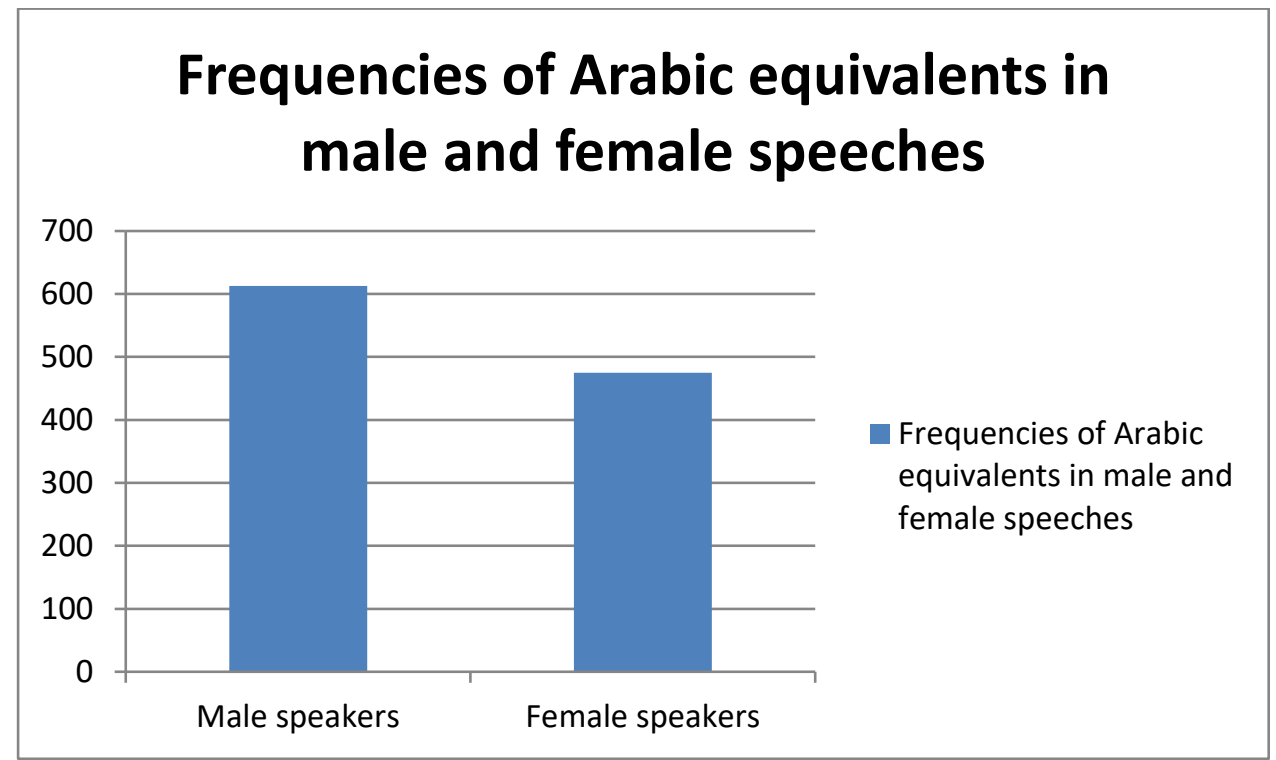

Although the participants tend in general to use English loanwords, frequency analyses show significant differences between men and men in adopting these loanwords. In talking about fashion, for instance, English loanwords are highly frequent in female speeches. Men, on the contrary, use more English loanwords in talking about sports and football.

Table 2 - The use of English loanwords in male and female's speeches

\begin{tabular}{|l|l|l|}
\hline Topics & Male & Female \\
\hline Computer \& technology & 167 & 191 \\
\hline
\end{tabular}




\begin{tabular}{|l|l|l|}
\hline Social media & 179 & 201 \\
\hline Clothes \& Fashion & 48 & 112 \\
\hline Greetings & 271 & 421 \\
\hline Education & 40 & 60 \\
\hline Banking & 38 & 44 \\
\hline Sports \& Football & 121 & 86 \\
\hline Miscellaneous & 10 & 22 \\
\hline Foods \& Drinks & 72 & 73 \\
\hline Cinema \& Music & 55 & 53 \\
\hline
\end{tabular}

A frequency distribution analysis of the use of men and women of English loanwords is shown below.

Figure 9 - A frequency distribution analysis of the use of men and women of English loanwords

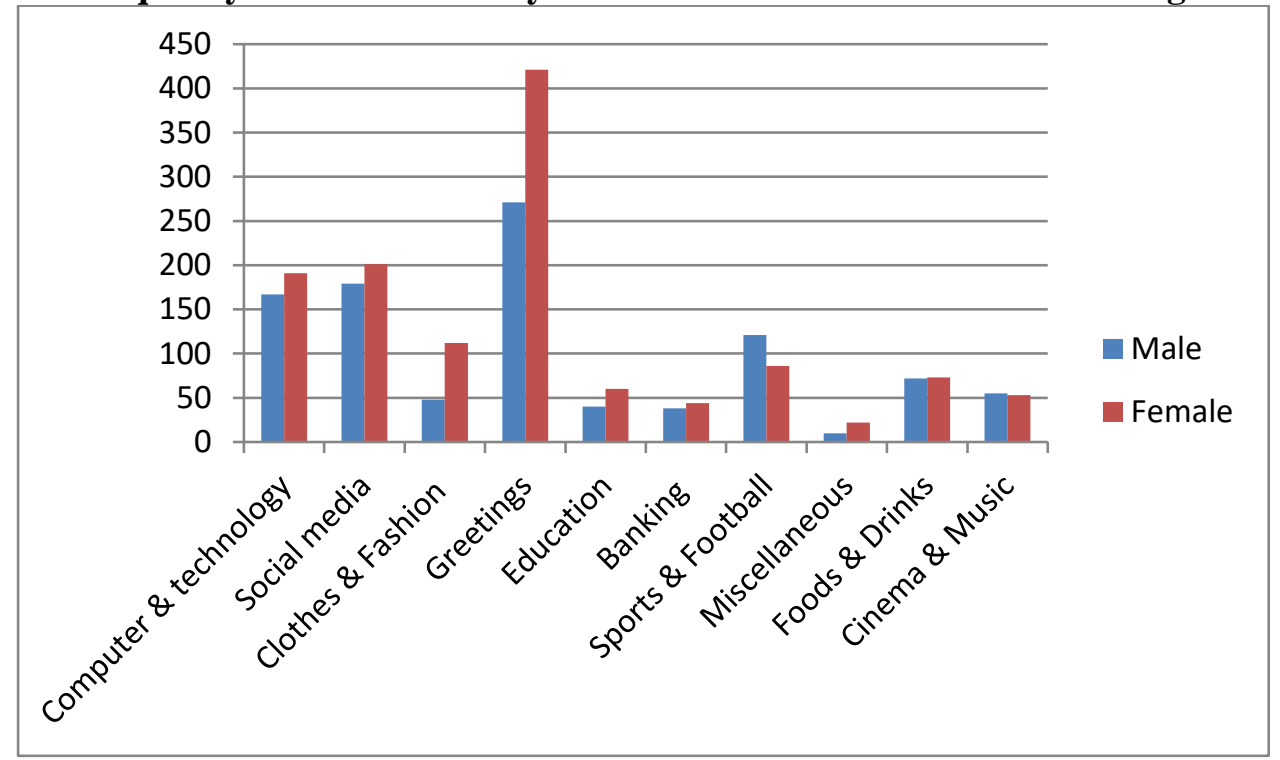

As shown in the figure above, the biggest difference between male and female in relation to the use of English loanwords is assigned to clothing and fashion. Expressing greetings comes second. Frequencies of English loanwords in male speeches outnumber the frequencies of female speeches in football. There is no significant difference between male and female speakers in talking about foods, drinks, cinema, and music. These are very slight differences.

As statistical results indicate, there are generally significant differences between male and female speakers in relation to the frequency of the use of English loanwords. Saudi female speakers use English loanwords more frequently than male speakers. Concerning the way these English loanwords are used in SCA, it has been observed that there are morphological adaptations English loanwords undergo when used and adopted by Saudi speakers. The rationale is that the morphological system of Arabic is different from English (Ryding, 2002; Watson, 2002). Therefore, speakers make morphological changes within these words. Generally speaking, it can be claimed that male and female Saudi speakers use English loanwords differently. In other words, differences 
between male and female speakers in the way English loanwords are adapted in SCA. This section discusses the main morphological adaptations English loanwords undergo when used in SCA and how male and female speakers use them differently.

1. Results indicate that Saudi speakers use the Arabic definite article [al] ال with English loan nouns. That is, they treat the English loan nouns as Arabic words. Examples are computer, mobile, tweets, and goal keeper. An interesting feature, however, is that, this rule cannot be applied to English words that can be also used as nouns and verbs. The Arabic definite article ال, however, is not used with the English loanwords reply, follow, and friend which are used in English as nouns and verbs. In the speeches of both male and female speakers, the Arabic definite article is attached to the English loan nouns with no difference. Both male and female speakers say elbank for the bank, elblouse for the blouse and so on. However, the Arabic definite article has never been used by any male or female speakers with words such as reply, follow, and friend. By the way, these words are used in SCA as only nouns. They have not been reported in the data to be used as verbs.

2. One of the main differences within linguistic adaptation is the use of the English loanwords: like, share, and follow. All these words are used only as nouns in SCA. They come as direct objects of the Arabic transitive verbs يعمل [yemel] and بسوي [yu:sawi] meaning to do. The former however is used by male speakers while the latter is used by female speakers. In this way, there is a linguistic diversity based on sex in relation to morphological adaptation of the English loanwords.

3. Another difference between male and female speakers in relation to the way English loanwords are used and morphologically adapted in SCA is related to the plural system. Results show that male speakers generally tend to use broken plurals with English loanwords while female speakers tend to use feminine plurals. In Arabic, the plural system is composed of three categories: masculine plural, feminine plural, and broken plural (Maxos, 2000). Since grammatical gender is one of the main morphological features in Arabic, masculine nouns receive the suffix [u:n] while feminine nouns receive the suffix [a:t]. Both masculine and feminine plurals are classified as regular plural since there is a standard rule for adding an inflectional morpheme to end of the word to form the plural. Or some nouns, however, plural cannot be formed by adding [u:n] or [a:t]. These are assigned broken plural which is also known as irregular plural. Broken plural is normally formed by adding an infix to nouns. Infixes are accepted in Arabic. Female speakers say [sentra:t] موتورات for centers and motors respectively. Male speakers, on the other hand, say [sanater] سناتر and [mawath:r] مواتير for the two English loanwords.

4. Another difference between male and female use of English loanwords is also related to the plural system. Many male speakers prefer to use the English loan nouns as singular without any 
morphological changes. Instead, they use an additional (Arabic) word along with the English loan nouns to indicate the plural mark. Male speakers say [aghezet mobail] أجهزة موبايل and [aghezet kompju:tar] أجهزة كنبيوتر meaning mobile sets and computer sets respectively. Female speakers, on the other hand, tend to attach the feminine plural morpheme [a:t] or simply use the English plural form as it is. English plural forms are also used with a higher frequency in the data of female speakers.

\section{RESULTS AND DISCUSSIONS}

Results indicated that Saudi speakers use English loanwords in expressing greetings and talking about computer technology, social media, football, and fashion. Although greetings come first, however, this should not be generalized. The idea is that the data is based on phone conversations where speakers have to use greeting expressions at the beginning and end of the conversations whether in Arabic or English. In this context, the results of this study agree with the main bulk of the studies which have been carried out on the use of English loanwords either on the regional dialects of Arabic as well as colloquial Arabic (Abushabib, 2016; Baker, 1987; Darwish, 2015, Hafez, 1996; Hashim, 2011) or other languages such as Japanese (Evans, 1997; Irwin, 2011; Maynard, 1997; Miura, 2011), Spanish (Garcia, 2013; González, 1996; ), Dutch (Booji, 2001; Meurs and Hornikx, 2014; Zenner, 2015), and Chinese (Hui and Oh, 2015; Zia and Miller, 2013). It is generally agreed that English loanwords are very frequently used by speakers of many languages all over the world in talking about computer, technology, education, and social media. The rationale is that many of these words such as tweet, status, friend, unfriend, computer, internet, Wi-Fi, football are culturally bound with English. Many of these words have been also gained popularity first as English words and the equivalents of recipient languages are not that popular. So many speakers use them for familiarity. The implication here is that the high frequency of English loanwords compared to their Arabic counterparts reflects the ease with which English loanwords are used in SCA. The idea that speakers have shared concepts about English loanwords makes it easier for communication to adopt these loanwords in their talks and speeches.

Although the statistical results cannot say what are the reasons that Saudi speakers tend to use English loanwords more frequently than their Arabic equivalents or counterparts, some reasons can be suggested. First, the use of English loanwords helps users to avoid ambiguity. In Arabic, for instance, the word boots is translated as حذاء عالي. It can be understood as high heels shoes. In this way, speakers use English loanwords so they are not misunderstood. It is easier therefore for listeners to recognize and understand what the speaker is talking about. This agrees with Hock's (1991) argument that loanwords fill a lexical gap in the recipient language. Second, it can be 
suggested that female speakers tend to be more prestigious by using English loanwords. It is believed that English is of a higher status. The belief is that people borrow from languages that they look up to. Saudi female speakers wish to appear as ones of a higher status. Therefore, they tend to use English loanwords. The implication is that Saudi female speakers tend to use English loanwords in order to be perceived in a more favorable way by their addressees or recipients. Third, many English loanwords are now very popular among Saudi speakers. Many of these words are associated with social media. These words are instantly recognizable and understood by many people. These words are even more popular than their Arabic equivalents. Therefore, speakers tend to use these English loanwords simply because of familiarity.

Concerning the relationship between gender/sex and the use of English loanwords in SCA, the results reported in this study agree with previous studies in the sense that women generally use loanwords more frequently than men do. The higher frequency of English loanwords in women speeches may be interpreted that female speakers want to appear as more prestigious than men. It can be also suggested that the adoption of English loanwords by female speakers has a social function. In Saudi Arabia, the society is generally described as a male-dominated society where women are still denied many rights women in all other countries have. The use of English loanwords may be interpreted as a way to assert the modern identity of women and that global economic and political changes should find their way to the Saudi community. In this context, it can be claimed that there is a close relationship between gender, language, and identity. This asserts the assumption that there is a close relationship between loan functions and speakers' characteristics of gender. The sex of the speaker then turns out to be an important factor in determining the frequency and distribution of English loanwords.

In spite of the fact that Saudi female speakers use English loanwords more frequently than male speakers, one interesting result is that male speakers tend to use English loanwords more frequently in talking about football. There is a great difference in relation to the adoption of English loanwords between male and female speakers. It can be suggested that they want to emphasize distinctiveness and/or to shape addressee's impressions.

Results also indicate clearly that the sex or gender of the speaker plays an important role in determining the way English loanwords are used in SCA. Although both male and female speakers use morphological changes or adaptations within English loanwords, there are some cases where there is a linguistic diversity for gender reasons. The morphological adaptations are usually used by speakers to make the use of loanwords easier. This finding agrees with the established sociolinguistic research in the sense that gender is a considerable variable in linguistic diversity (Meyerhoff, 2015; Trudgill, 2000; Wardhaugh, 2000). 


\section{Conclusion}

This study addressed the relationship between sex as one of the social variables that result in linguistic diversity as well as the adoption and use of English loanwords by Saudi speakers. The study investigated the ration of English loanwords as opposed to their Arabic equivalents and whether there is a correlation between sex and the use of English loanwords in SCA. In order to achieve the study purposes and objectives, a corpus of English loanwords in SCA was built. Data was abstracted from phone conversations derived from one of the most watched TV shows in Saudi Arabia. Results indicate that English loanwords are frequently used in CAS and that sex is a significant variable in the use of English loanwords in terms of frequency and morphological adaptations. Female speakers use English loanwords more frequently. Furthermore, female speakers use English loanwords in a way that differs to some extent from male speakers. The main findings of the study can be summarized as follows.

Saudi speakers use English loanwords more frequently than their Arabic equivalents. There is a tendency of Saudi speakers to adopt English loanwords in their conversations and speeches. Although reasons maybe different; English loanwords represent a considerable linguistic observation/ phenomenon in SCA. English loanwords that are common in the speeches and conversations of Saudi speakers are associated with greetings, banking, study/education, fashion, computer, technology, sports (especially football), and social media. The assumption however is that there is a shared knowledge among speakers and recipients or addressees about the meanings of English loanwords. These shared concepts make it easier for Saudi speakers to adopt English loanwords in their speeches.

It was also found out that generally speaking female speakers use English loanwords more frequently than male speakers. it can be suggested that the higher frequency of English loanwords in the speeches and conversations of Saudi female speakers may be due to the idea that they want to seem more prestigious than men. It can also be suggested that the use of English loanwords serves a social and political purpose. Saudi female speakers assert their modern linguistic identity by using a modern version of language. The implication here anyway is that there is a close relationship between the functions of English loanwords and speakers' characteristic of gender. The sex or gender of the speaker is an important factor in determining the frequency and distribution of English loanwords in SCA.

Concerning morphological adaptations within English loanwords in SCA, it was found out that both male and female speakers use specific morphological changes with these loanwords. Although they share many morphological adaptations, there are still some differences between male 
and female speakers in relation to the way English loanwords are morphologically adapted and used in SCA. This again asserts the role of sex or gender in linguistic diversity and the way language is used.

\section{LIMITATIONS AND RECOMMENDATIONS}

Over the past decades, lexical influence of English on Arabic varieties including Saudi Arabic is significant. Although different studies have been dealing with issues of the reasons of the adoption and linguistic adaptation of English loanwords in Arabic in general, very little has been done on Saudi Arabic. This study tended to complement this research tradition by focusing only on the role of sex on the use of English loanwords in SCA. The study, however, is limited in scope. It addressed the relationship between sex and the use of English loanwords in SCA. It also was limited to the investigation of the morphological adaptations English loanwords undergo when used by Saudi speakers. It is recommended thus that future studies pay more attention to speaker-related and context-related features contributing to the use of English loanwords in Saudi Arabic. It is also suggested that future studies should address the historical development of English loanwords in Arabic in general and SCA in particular. The idea is that numerous studies have indicated that globalization has brought about unprecedented changes within Arabic and SCA due to the adoption of English loanwords. However, no study investigated the use and adoption of English loanwords before and after the emergence of globalization. Since this study addressed only morphological changes and adaptations, studies need to address phonological and syntactic adaptations that English loanwords undergo when used in Arabic and SCA. The idea is also limited to comparing the use of English loanwords to their Arabic equivalents or counterparts. Data indicate that there have been many cases of overlap between English loanwords and Arabic equivalents. Further research should address the issue of overlap between English loanwords and their Arabic equivalents in SCA. Finally, studies need to address the implications of the adoption of English loanwords to second language acquisition. In Saudi Arabia, many critics and religious leaders have been talking about the risks of the widespread of English loanwords in MSA and in the SCA used by Saudi people. However, no scholarly research has been done on how to explore ways by which the adoption of English loanwords be integrated into the teaching of English for EFL Saudi learners.

\section{REFERENCES}

Abdel-Rahman, W. (1991). A Critical Linguistic Study of Lexical Borrowing in Arabic and English. Journal of King Saud University, 3(2), 33-66. 
Abushihab, I. (2016). Foreign Words in Jordanian Arabic among Jordanians Living in Irbid City: The Impact of Foreign Languages on Jordanian Arabic. Journal of Language Teaching and Research, 7(2), 284-292.

Alahmadi, S. D. (2015). Loanwords in the Urban Meccan Hijazi Dialect: An Analysis of Lexical Variation according to Speakers' Sex, Age and Education. International Journal of English Linguistics, 5(6), 34-58.

Alosh, M. (2005). Using Arabic: A Guide to Contemporary Usage. Cambridge Cambridge University Press.

Al-Sameray, A. (2011, December 8-10, 2011). The Influence of Biculturalism on Arabic Language. Paper presented at the Proceedings of the Linguistic Changes of Arabic in the Age of Globalization Al-Khalil, the West Bank.

Armstrong, N. (2005). Translation, Linguistics, Culture: A French-English Handbook. Clevedon, Buffalo and Toronto: Multilingual Matters Ltd.

Auer, P. (2003). Code-switching in conversation : language, interaction and identity. London ; New York: Routledge.

Baker, M. (1987). Review of Methods Used for Coining NewTerms in Arabic. META, 32(2), 186188.

Baugh, A. C., \& Cable, T. (1989). A History of the English Language (3rd ed.). London: Prentice Hall International.

Booij, G. (2001). English as the lingua franca of Europe: A Dutch perspective. Lingua e Stile, 36(2), 347-357.

Brustad, K. (2000). The Syntax of Spoken Arabic: A Comparative Study of Moroccan, Egyptian, Syrian, and Kuwaiti Dialects. Washington: Georgetown University Press.

Campbell, L. (2013). Historical Linguistics: An Introduction (Third edition. ed.). Edinburgh: Edinburgh University Press.

Cannon, G. (1994). The Arabic Contributions to the English Language: An Historical Dictionary. Wiesbaden: Harrassowitz Verlag.

Carroll, T. (2013). Language Planning and Language Change in Japan : East Asian Perspectives.

Chejne, A. G. (1969). The Arabic language: its role in history: Minneapolis: University of Minnesota Press.

Coposescu, L. (2010). Discourse Analysis of Communication in International Companies. In A. James (Ed.), Globalization in English studies. Newcastle: Cambridge Scholars.

Corriente, F. (2008). Dictionary of Arabic and Allied Loanwords : Spanish, Portuguese, Catalan, Galician and Kindred Dialects. Leiden: Brill.

Crystal, D. (2003). English as a Global Language (2nd ed. ed.). Cambridge ; New York:

Cambridge University Press. 
Daher, J. (2003). Lexical Borrowing in Arabic and English. The Vocabula Review 5(5).

Darwish, H. (2015). Arabic Loan Words in English Language. Journal Of Humanities And Social Science, 20(7), 105-109.

Durkin, P. (2015). Borrowed Words: A History of Loanwords in English (First edition. ed.). Oxford Oxford University Press.

Evans, T. (1997). A Dictionary of Japanese Loanwords: Greenwood Publishing Group.

García, C. L. (2013). The English Language and Anglo-American Culture: Its Impact on Spanish Language and Society. Newcastle upon Tyne: Cambridge Scholars Publishers.

González, F. R. (1996). Spanish Loanwords in the English Language: A Tendency Towards Hegemony Reversal: Walter de Gruyter.

Gu, S. a. (2013). A cultural history of the Arabic language. North California; London: McFraland Publishers.

Hafez, O. (1996). Phonological and Morphological Integration of Loanwords into Egyptian Arabic. Égypte/Monde arabe, 27-28, 383-410.

Hashim, A. (2011, December 8-10, 2011). Standard Arabic and Recent Dialects in the Age of Globalization. Paper presented at the Proceedings of the Linguistic Changes of Arabic in the Age of Globalization Al-Khalil, the West Bank.

Haspelmath, M. (2009). Lexical Borrowing: Concepts and Issues. In M. Haspelmath \& U. Tadmor (Eds.), Loanwords in the World's Languages: A Comparative Handbook (pp. 35-55). Berlin, Germany: De Gruyter Mouton.

Haspelmath, M., \& Tadmor, U. (Eds.). (2009). Loanwords in the World's Languages: A Comparative Handbook. Berlin, Germany: De Gruyter Mouton.

Hassan, W. (2015). The Lexicalization of English Loanwords into Egyptian Arabic. In G. Senosiáin (Ed.), Lenguas, lenguaje y lingüística (pp. 243-259): Servicio de Publicaciones de la Universidad de Navarra.

Haugen, E. (1950). The Analysis of Linguistic Borrowing. Language, 26, 210-231.

Hock, H. H. (1991). Principles of historical linguistics (2nd ... ed. ed.). Berlin: Mouton de Gruyter.

Hoffer, B. L. (2002). Language Borrowing and Language Diffusion: An Overview. Intercultural Communication Studies, XI(4).

Holes, C. (2004). Modern Arabic: Structures, Functions, and Varieties Georgetown: Georgetown University Press.

Hui, Y., \& Oh, M. (2015). Adaptation of English Stops into Mandarin Chinese. Linguistic Research, 32(2), 403-417. 
Ibrahim, Z. (2006). Borrowing in Modern Standard Arabic. In R. Muhr (Ed.), Innovation and Continuity in Language and Communication of Different Language Cultures (Vol. 9, pp. 235-260).

Frankfurt: Peter Lang.

Ibrahim, Z. (2009). Beyond Lexical Variation in Modern Standard Arabic: Egypt, Lebanon and Morocco. Newcastle upon Tyne: Cambridge Scholars Publishing.

Irwin, M. (2011). Loanwords in Japanese. Amsterdam; Philadelphia: John Benjamins Publishing Company.

Ismaeel, S. A. (2005). The Influence of Globalization on Arabic. International Islamic University, Malaysia.

James, A. (2010). Globalization in English Studies. Newcastle: Cambridge Scholars.

Kachru, B. B. (1983). The Other Tongue: English Across Cultures. Oxford: Pergamon.

Kaplan, R. B., \& Baldauf, R. B. (2005). Language Planning and Policy in Europe: Clevedon : Multilingual Matters, 2005-.

Kashgary, A. (2014). The paradox of translating the untranslatable. Riyadh: Saudi Arabia: Jarir

Kay, G. (1995). English Loanwords in Japanese. World Englishes, 14(1), 67-76.

Kemmer, S. (2004). Loanwords: Major Periods of Borrowing in the History of English Retrieved April 20, 2016, 2016, from http: // www .ruf. rice.edu/ Kemmer/ Words/ loanwords.html

Khalil, G. (1984). Lexical Borrowing From French And English By Egyptian Colloquial Arabic. Unpublished PhD, American University, Cairo.

Labov, W. (2011). Principles of Linguistic Change: Cognitive and Cultural Factors. Oxford: Wiley-Blackwell.

Lancioni, G., \& Bettini, L. (2011). The word in Arabic. Leiden: Extenza Turpin.

Maxos, H. (2000). Modern Arabic Grammar. Damuscus: Dar Al-Kitab.

Maynard, S. K. (1997). Japanese Communication: Language and Thought in Context. Hawaii: University of Hawaii Press.

Meurs, F., \& Hornikx, J. (2014). English Loanwords and their Counterparts in Dutch Job Advertisements: An Experimental Study in the Assocition Overlap In E. Zenner \& G. Kristiansen (Eds.), New Perspectives on Lexical Borrowing: Onomasiological, Methodological and Phraseological Innovations (pp. 171-190): Walter de Gruyter.

Meyerhoff, M. (2015). Introducing sociolinguistics. London: Routledge.

Miura, A. (2011). English Loanwords in Japanese: A Selection: Tuttle Publishing.

Morrow, P. R. (2007). The Users and Uses of English in Japan. World Englishes, 6(1), 49-62.

Moshref, O. (2009). Grammatical Gender Assignment of English and French Loan Words in Egyptian Arabic. Arabic Linguistics Symposium Austin, Texas, United States of America. 
Myers-Scotton, C. (2006). Multiple Voices: An Introduction to Bilingualism. Oxford: Blackwell.

Ngom, F. (2002). Linguistic Borrowing as Evidence of the Social History of the Senegalese Speech Community. International Journal of Sociology of Language, 158, 37-51.

Philips, S. U., Steele, S., \& Tanz, C. (1987). Language, Gender and Sex in Comparative Perspective. Cambridge: Cambridge University Press.

Qasim, M. (2009). At-tarjamatu fil-'asr il-'abāsī wa-dawraha fỉ tanaw'i il-'ūlūmi wa ma'ārifi 'inda al-'arab (Translation in the Abbasi Age). Afāq ath-thqafah wat-turath (Horizons of Culture and Heritage), 66, 55-78.

Qinai, J. (2000). Morphophonemics of Loanwords in Arabic. Studies in the Linguistic Sciences $30(2)$.

Romaine, S. (1989). Bilingualism. Oxford: Basil Blackwell.

Rosenhouse, J., \& Kowner, R. (2013). Globally Speaking: Motives for Adopting English Vocabulary in Other Languages: Multilingual Matters.

Ryding, K. C. (2005). A reference grammar of modern standard Arabic. Cambridge: Cambridge University Press.

Sachdev, I., \& Giles, H. (2004). Bilingual accommodation. In T. K. Bhatia \& W. C. Ritchie (Eds.), The Handbook of Bilingualism (pp. 353-378). Oxford: Blackwell.

Stanlaw, J. (1983). English in Japanese Communicative Strategies. In B. Kachru (Ed.), The Other tongue : English across cultures. Oxford: Pergamon.

Suleiman, S. (1985). Jordanian Arabic between Diglossia and Bilingualism: Linguistic analysis: John Benjamins Publishing.

Talbot, M. M. (2010). Language and Gender (2nd ed. ed.). Cambridge: Polity.

Taylor, W. (1933). Arabic Words in English. London: Clarendon.

Thomason, S. G. (2001). Language Contact. An Introduction. Edinburgh: Edinburgh University Press.

Trudgill, P. (2000). Sociolinguistics: An Introduction to Language and Society. London: Penguin Books.

Versteegh, C. H. M. (2014). The Arabic language. Edinburgh: Edinburgh University Press.

Versteegh, K. (2014). The Arabic Language (Second Edition ed.). Edinburgh: Edinburgh University Press.

Wardhaugh, R., \& Fuller, J. M. (2015). An Introduction to Sociolinguistics (Seventh edition. ed.). Chichester: Wiley Blackwell.

Watson, J. C. E. (2002). The phonology and morphology of Arabic. Oxford: Oxford University Press. 
Winter-Froemel, E. (2007). Loanword Adoption versus Adaptation: Two Types of Conformity. Newcastle Working Papers in Linguistics.

Xia, X., \& Miller, E. (2013). Reconstructing gender ideologies of English loanwords in Chinese. Language \& Communication, 33(3), 214-220.

Yarshater, E. (1998). The Persian Pressence in the Islamic World. In R. G. Hovannisian \& G. Sabagh (Eds.), The Persian Presence in the Islamic World (pp. 4-125). Cambridge: Cambridge University Press.

Yule, G. (2006). The study of language (3rd ed.). Cambridge: Cambridge University Press.

Zenner, E. (2015). A sociolinguistic analysis of borrowing in weak contact situations: English loanwords and phrases in expressive utterances in a Dutch reality TV show. International Journal of Bilingualism, 9(3), 333-346. 